\title{
Hepatitis B and C viruses' infection and associated factors among pregnant women in the Amhara region, Ethiopia: implications for prevention of vertical transmission.
}

\author{
Mulat Dagnew ( $\nabla$ dagnewmulat@gmail.com ) \\ University of Gondar https://orcid.org/0000-0001-5174-8519 \\ Yihenew Million \\ University of Gondar \\ Mucheye Gizachew \\ University of Gondar
}

Setegn Eshetie

University of Gondar

Gashaw Yitayew

Amhara National Regional Health Bureau

Lakachew Asrade

Bahir Dar University

Mulat Adefris

University of Gondar

\section{Feleke Moges}

University of Gondar

Moges Tiruneh

University of Gondar

\section{Research Article}

Keywords: Pregnant women, HBV, HCV, Associated factors, Amhara region

Posted Date: May 27th, 2020

DOl: https://doi.org/10.21203/rs.3.rs-30519/v1

License: (1) This work is licensed under a Creative Commons Attribution 4.0 International License.

Read Full License 


\section{Abstract \\ Background}

Hepatitis virus infection is a major public health burden and silent killer disease in sub-Saharan Africa, including Ethiopia. Despite the recommendations of the World Health Organization, screening for hepatitis $B$ virus $(\mathrm{HBV})$ and hepatitis $\mathrm{C}$ virus $(\mathrm{HCV})$ in pregnant women is not done routinely in public health institutions. Therefore, this study aimed to determine the burden of HBV and HCV and its associated factors among pregnant women in the Amhara region, Ethiopia.

\section{Methods}

A total of 1121 pregnant women were enrolled in the study. Data on sociodemographic and associated factors were collected using a structured questionnaire. Blood was collected from the pregnant women, and serum samples were tested for HBsAg and anti-hepatitis $\mathrm{C}$ virus antibody (anti-HCV) using ELISA. The status of HIV-infected pregnant women was collected from the records of their charts. SPSS version 20 was used for data analysis, and a binary logistic regression model was used to assess the relationship between factors associated with HBV and HCV infection.

\section{Results}

The seroprevalence of HBsAg and anti-HCV antibody were $4.6 \%$ and 1.6, respectively. The co-infection rate of HBV/HCV was $1.4 \%$ (1/69). Ten out of $52 \mathrm{HBV}$ positive cases $(19.2 \%)$ were co-infected with HIV. Only $20(1.8 \%)$ pregnant women had the HBV vaccine. Interestingly, pregnant women with a history of multiple sexual partners $(\mathrm{AOR}=3.2,95 \% \mathrm{Cl}, 1.7-7.6)$, blood transfusion $(\mathrm{AOR}=7.6,95 \% \mathrm{Cl}, 2.9-16.9)$, family history of HBV (AOR = 3.5, 95\% Cl,1.7-7.6), being HIV-positive ( $\mathrm{AOR}=2.5,95 \% \mathrm{Cl}, 1-5.9)$, and tattooing $(A O R=2,95 \% \mathrm{Cl}, 1-3.8)$ were significant predictors of $\mathrm{HBV}$ infection.

\section{Conclusions}

$\mathrm{HBV}$ and $\mathrm{HCV}$ infections were intermediate among pregnant women; risk factors were responsible for the majority of cases. Infants born from these infected mothers are at risk of infection. This calls for integration of HBV prevention into the PMTC of HIV. Thus, the provision of health education on HBV and HCV transmission, vaccination, and screening of all pregnant women routinely is essential for PMTCT.

\section{Background}

Viral hepatitis is a major public health burden all over the world. It is responsible for an estimated 1.4 million deaths, which is greater than the death toll of 1.2 million to that of HIV. Globally, 248 million and 150 million people have chronic HBV and HCV infections and the cause of death for 780,000 and 
350,000 people, respectively [1]. HBV and HCV infections are highly endemic in developing regions of Asia and Africa. The highest seroprevalence of hepatitis B surface antigen ( $\mathrm{HBsAg})>8 \%$ and antihepatitis $\mathrm{C}$ virus (anti-HCV) antibody $>3.5 \%$ have been reported in these regions [2,3]. Despite its high prevalence of HBV and HCV, it remains under-reported and lacks of reliable epidemiological data in most African countries, including Ethiopia. Globally, less than $5 \%$ of people are aware of infected by hepatitis virus infection [1]. The majority of hepatitis infected individuals remain asymptomatic or apparently healthy, transmit the virus to other persons, and die of the infection without notice; it is a silent killer [4].

HBV is highly contagious and hundred times more infectious than HIV, transmitted horizontally through infected blood, blood products, unprotected sex, unsafe injection, tattooing, and from infected mother-tochild vertically, before birth, during birth and after birth $[5,6]$. Mother-to-child transmission (MTCT) of HBV remains a major source of chronic infection in endemic countries [7]. A pregnant woman positive for HBsAg, hepatitis B e antigen (HBeAg), and HBV viral load of deoxyribonucleic acid (DNA) (> $200,000 \mathrm{IU} / \mathrm{mL}$, equivalent to $6 \log$ copies $/ \mathrm{mL}$ ), the chance of MTCT increases and reaches $90 \%$ [8]. In Africa, about $70-90 \%$ of infants infected before 1 year of age develop chronic HBV infection, liver cirrhosis, hepatocellular carcinoma, and early death in children [9]. To prevent MTCT, screening, early case detection, initiation of treatment of pregnant women, and provision of active birth dose HBV and passive hepatitis B immunoglobulin (HBIG) vaccines within 24 hours are widely recommended for infants born to HBsAg-positive pregnant mothers $[9,10]$.

$\mathrm{HCV}$ is transmitted mainly through parenteral routes such as infected blood transfusion, intravenous drug use or blood product, therapeutic injection, intravenous drug use, acupuncture, tattooing, ear piercing and transmission during sexual contact and vertically from infected-mother-to-child [5, 11, 12].Vertical transmission of HCV from mother-to-child contributes to $10 \%$ of cases and lower than other viral pathogens such as HIV and HBV [13]. Drugs like direct-acting antiviral agents (DAA) are effective for curing up to $70 \%$ of HCV-infected persons; however, contraindicated during pregnancy $[11,13]$. Currently, there is no effective vaccine for HCV and no effective means of preventing MTCT of HCV.

Viral hepatitis during pregnancy is associated with a high risk of maternal, fetal, and neonatal complications such as still birth, abortion, premature birth, and low birth weight [14]. Despite the significant health burden, it places on communities, viral hepatitis is an ignored health problem and has given little attention in Ethiopia. In Ethiopia, there is a lack of reliable national and sub-national epidemiological data on both HBV and HCV among pregnant women. Though few studies have been conducted in our country with small sample sizes. The prevalence of HBsAg among pregnant women varies considerably from $2.4-8.4 \%$ and anti-HCV antibody $0.6-8.1 \%$, respectively [15-18]. In Ethiopia, the co-endemicity of HBV, HCV, and HIV and the same route of transmission and co-infections in pregnancy resulted in increased morbidity, mortality and vertical transmission of these viruses $[4,19]$.

Screening for hepatitis during pregnancy is important for both the mother and the fetus, widely recommended and giving prophylaxis for those who are positive $[1,20,21]$. HIV and syphilis are routinely screened in Ethiopia. There is a well-organized and standard PMTCT of HIV in the country. Moreover, the 
World Health Organization (WHO) recommended PMTCT for HIV, syphilis and HBV [22]. Despite this recommendation, Ethiopia has not scaled up HBV PMTCT in the country. Currently, screening for these viruses is not a routine practice in health institutions in Ethiopia due to a lack of diagnostic kits and high cost of treatment. There are no current multicenter studies with large sample sizes on HBV and HCV among pregnant women in Ethiopia, specifically in the Amhara region, Ethiopia. Therefore, this study aimed to assess the magnitude of HBV and HCV infections and associated factors in the first trimester of pregnant women in the Amhara region, northwest Ethiopia.

\section{Materials And Methods}

\section{Study area, design, and period}

A cross-sectional study was conducted in the Amhara regional referral hospitals, namely, the University of Gondar Comprehensive Specialized Hospital, Felege Hiwot Specialized Hospital, and Debre Markos Hospital. The University of Gondar Comprehensive Specialized Hospital is located in Gondar, $750 \mathrm{~km}$ northwest of Addis Ababa. The hospital serves more than 5 million inhabitants in the Amhara region. The Felege Hiwot Comprehensive Specialized Hospital is located in Bahir Dar, the capital city of the Amhara region. It serves as a referral hospital in the Amhara region. Debre Markos Hospital is Zonal Hospital, which serves two million people in the East Gojam Zone. The study was conducted from May1,2018 to September 30,2019.

\section{Study population, sample size, and sampling technique}

The study population were all pregnant women who were attending the University of Gondar Compressive Specialized Hospital (UOGCSH), Felege Hiwot Comprehensive Specialized Hospital (FHCSH) in Bahir Dar and Debre Markos Hospital (DMH) during the study period. All pregnant women whose urine tests positive for human gonadotrophic hormone (HCG) and first trimester were included in the study. Those pregnant women with unknown gestational age and seriously ill were excluded from the study. The sample size was calculated using a single proportion formula. The formula is $n=z^{2} / d^{2}(p(1-q) / w 2$. The assumption $95 \%$ confidence interval, $1.96 \%$, margin of error $2 \%$, and prevalence of $50 \%$. Including $5 \%$ of the 1067 nonresponse rates. Finally, the sample size was 1121 . A systematic sampling technique was used to select pregnant women in the antenatal clinic (ANC).

\section{Data collection}

Sociodemographic and clinical characteristics of pregnant women and associated factors were collected using a pretested structured questionnaire by trained experienced senior Midwifery nurses.

\section{Sample collection, transportation, and processing}

After getting permission from the pregnant women, five $\mathrm{mL}$ of venous blood was collected from each pregnant woman by a trained experienced senior laboratory technologist. Serum was separated within $8 \mathrm{~h}$ by centrifugation of whole blood at $3000 \mathrm{rpm}$ for $10 \mathrm{~min}$. Serum samples were separated and 
transferred to a nuck tube and stored at $-800_{C}$ in a refrigerator until being processed by Enzyme Linked Immuno Sorbent Assay (ELISA). Serum samples collected from Felege Hiwot Comprehensive Specialized and Debre Markos Hospital were transported to the University of Gondar Comprehensive Specialized Hospital using cold boxes with dry ice. Hepatitis B surface antigen (HBsAg) from the serum of each pregnant woman was determined using ELISA according to the manufacturer's instructions (Linear Chemicals, S.L.U., Spain). Anti-HCV antibodies were tested using commercially available EIISA kits (DIALB Diagnostics $\mathrm{GmbH}$, Vienna, Austria) according to the manufacturer instructions. The results were read in a microplate reader at $450 \mathrm{~nm}$ within $30 \mathrm{~min}$. In addition, the HIV test results of the pregnant women were also collected from their medical records. The HIV test was performed using rapid test kits following the national test algorithm. HIV1/2 STAT PACK was used as a screening test kit, followed by ABBON. If both test kits were discordant, repeated again. If both were positive, the third test (tie breaker BIOLINE) will be performed if positive the result reported as positive.

\section{Data quality}

The data collectors were trained on the study protocol (client approach, data collection procedures, and quality issues) prior to the start of the study. To ensure the quality of the data, questionnaires were prepared in English and translated into Amharic and retranslated back into English. The questionnaires were pretested before two weeks in the study time among $5 \%$ of pregnant women in the Poly Health Center in Gondar Town. The collected data were checked for consistency and accuracy. The standard operating procedures were strictly followed during blood sample collection, storage, and analytical process. The storage conditions and expiration date of the reagents were checked. The ELISA test was controlled by house internal known positive and negative controls processed using Wanti. Both positive and negative controls were run along with samples prepared by the manufacturer and following the manufacturer's instructions.

\section{Data Analysis}

Before data entry, the collected data were checked for completeness, consistency, and coded manually. Data were entered into SPSS version 20, cleaned, and recoded. Sociodemographic characteristics were analyzed using descriptive statistics such as frequencies, mean, and standard deviation. Bivariate logistic regression was used to determine the association between the outcome variable and explanatory variables. All variables in the bivariate logistic regression model whose $p$-value less than or equal to 0.2 were included in the multivariate logistic regression model. The adjusted odds ratio (AOR) with a 95\% confidence interval was used to check the strength of the association. Model fitness was done using Hosmer and Lemeshow statistics. Variables with a p-value $<0.05$ were considered statistically significant with a $95 \%$ confidence interval.

\section{Results}

\section{Sociodemographic characteristics}


A total of 1121 pregnant women participated in the study. Of these, $593(52.9 \%)$ of participants were from the University of Gondar Comprehensive Specialized Hospital and the rest were from Bahir Dar Comprehensive Specialized Hospital and Debre Markos Hospital. The mean age of study participants was 27.2 years with a standard deviation of 4.8 years. A large proportion of pregnant women 1094 (97.6\%) were married. Majority,895(79.8\%) of participants were from urban. Most of the study participants 1064 (94.9\%) were Orthodox Christians. More than half of the pregnant women 732 (65.3\%) were housewives. Only 20 (1.8\%) pregnant women were vaccinated for HBV before the study period (Table 1).

\section{Seroprevalence of HBV and HCV}

In this study,69 (6.2\%) pregnant women had serological evidence of either infections of HBV or coinfection with HCV. The overall prevalence of HBsAg among pregnant women was $52 / 1121,4.6 \%(95 \% \mathrm{Cl}$, 3.4-5.8\%). The prevalence of HBsAg was 7.2\% (32/447) and 2.8\% (17/593), 3.7\% (3/81) at Felege Hiwot Comprehensive Specialized Hospital, University of Gondar Comprehensive Specialized Hospital, and Debre Markos Hospital, respectively. While the overall seroprevalence of HCV antibody was 18/1121,1.6\% (95\% $\mathrm{Cl}, 0.9-2.4 \%)$. The highest HCV seroprevalence was 9.8\% (8/81) at Debre Makos Hospital, followed by the University of Gondar Comprehensive Referral Hospital 1\% (6/593), and Felege Hiwot Comprehensive Referral Hospital 0.9\% (4/448). The co-infection rates of HBV and HCV were 1.4\% (1/69).

The highest seroprevalence of HBsAg was $21.7 \%$ observed among unmarried pregnant women, followed by low income $9.4 \%$ and $6.2 \%$ rural residence; respectively (Table 2). Ten of $52 \mathrm{HBV}$ positive cases (19.2\%) were coinfected with HIV. The overall HBV/HIV coinfection rate was $0.89 \%$ (10/1121). There was no co-infection of HCV with HIV in this study. Three hundred and fifty-two (31.3\%) pregnant women had tattoos in their body parts. The highest seroprevalence among the associated factors was blood transfusion 7/34 (20.6\%), followed by multiple sexual partners 7/61(11.5\%) (Table 3).

\section{Factors associated with HBV infection in pregnant women}

Multivariate analysis showed that some of the variables were significantly associated with HBV infection (Table 3). Pregnant women who had HIV infection were (AOR 2.5; 95\% Cl: 1-5.9) times more likely to develop HBV infection than their counterparts. Similarly, pregnant women with a history of blood transfusion were (AOR 7.4; 95\% $\mathrm{Cl} 2.5-21.3$ ) more likely to have HBV infection than those who were not transfused blood. Pregnant women who had a history of sharing their tooth brush to others were 4.5 times (AOR 4. 5, 95\% Cl: 1.1-18) more likely to have HBV infection than those who did not share their tooth brush. Other variables like history of abortion, ear piercing, nose piercing, and surgery had no significant association with HBV infection.

\section{Discussion}

The World Health Organization has an ambitious plan to eliminate hepatitis viruses as a public health treat in 2030 [1]. Despite this, screening for HBV and HCV among apparently healthy pregnant women in Ethiopia is poor. Globally, more than $95 \%$ of hepatitis infected persons do not aware of their infection[1]. 
This number is substantial in developing countries where there is no routine screening for hepatitis. To eliminate hepatitis virus's early detection, prevention of transmission and initiation of treatment is very crucial. Screening of apparently healthy pregnant women is key for the prevention of vertical transmission. Thus, this study has a paramount significance and calls for Amhara regional health officials and even to the country level to work on screening for HBV and HCV among pregnant women routinely in public health institutions and integrate into the PMTCT of HIV.

This is the first large-scale study that examined seroprevalence of HBsAg and anti-HCV antibody and associated factors among pregnant women in the Amhara region, Ethiopia. Our study revealed that $4.6 \%$ of pregnant women were infected with HBV. This finding is in line with the WHO intermediate classification of HBsAg prevalence, which is $2-7 \%$ [23]. Moreover, it is similar to other studies conducted previously in Bahir Dar 4.4\%, Arba Minch 4.3\%, Dessie 4.9\%, and Egypt 5\%, South Africa 4.5\% [17, 24-27].

However, our findings are higher than those of studies done in the east Wolega zone 2.4\%, Dawuro 3.5\%, Addis Ababa 3\%, Eritrea 3.2\%, Germany $0.48 \%$, Turkey $2.1 \%$, and China 3.2\% [28-34]. On the other hand, our findings are lower than those studies done in Dire Dewa 8.4\%, Mekele 8\%, Hawasa 7.8\%, Yirgalem $7.2 \%$, Gambella $7.9 \%$, Harar $6.9 \%$, Tigray $5.5 \%$, Gambia $9.2 \%$, Tazania $8.03 \%$, Cameroon $6.6 \%$, and Ghana $12.9 \%[16,18,35-43]$. There is a variation among the prevalence's of our study with the studies that were conducted around the globe. The differences might be due to differences in cultural practices, socioeconomic status, availability of medical services, vaccination status, and diagnostic test kit employed in the study.

The overall seroprevalence of anti-HCV antibody in the present study was found to be $1.6 \%$. This finding is in agreement with the WHO intermediate criteria. According to WHO classification criteria graded as low, the HCV seroprevalence is $<1.5 \%$, intermediate $1.5 \%-3.5 \%$, and high $>3.5 \%$ [12]. This finding is comparable to a study conducted in southern Ethiopia 1.8\% [44]. However, our result is higher than Tazania 0.3\% [45] and Bahir Dar 0.6\% [17]. In contrast, our finding is lower than studies done in East Wolega $8.1 \%$ and Egypt 6.1\% [29,46]. On the other hand, anti-HCV antibody seroprevalence was $8.9 \%$ in Debre Markos Hospital, which is unexpectedly highest. This finding calls further study in Debre Markos Hospital and around the area in the community to further explore risk factors for a high prevalence of HCV. Variations in seroprevalence in Ethiopia and elsewhere might be due to the diagnostic test kit employed, awareness of transmission of HCV, exposure to risk factors, and geographic location.

Studies have documented that there was co-infection of HBV and HCV among pregnant women, similar to our findings [37, 44]. In contrast to this finding, no co-infection of these viruses was detected in studies conducted in Ethiopia and elsewhere [17, 29, 45].

Of the sociodemographic characteristics, younger age, and unmarried pregnant women had a significant association with HBsAg prevalence (Table 3 ). This might be due to, at younger age sexual activity being higher compared than in age groups of 25 years and above. This finding agrees with other studies in Gambella, Addis Ababa in Ethiopia [4, 41]. In contrast, studies have reported a high prevalence of HBsAg in pregnant women with increasing age [4]. Moreover, the probability of getting HBV infection in 
unmarried women is higher than that in their counterparts. This in line with a study conducted in Ethiopia [18]. This might be due to in Ethiopia, unmarried pregnant women have the possibility of having more than one sexual partner to get job opportunities and to get money as compared to married pregnant women. To the contrary of this study, a high positive HBsAg more likely in married pregnant women than in single and divorced [36]. The observed differences could be due to the sample size of the study participant, geographic location difference, and culture of population living in.

Among the various risk factors assessed, having multiple sexual partners, HIV, sharing toothbrush, family history of HBV, history of tattooing, and previous history of blood transfusion were significantly associated with HBV infection (Table 3). Pregnant women with multiple sexual partners had 3 times (AOR3.2; 95\% Cl: $1.3-7.6 \%$ ) more likely to develop HBV infection than their counterparts. This finding is similar to other studies [17, 24, 40-43]. Blood transfusion has been recognized as a major risk factor for transmission of HBV throughout the world. Pregnant women with a history of blood transfusion previously had almost 8 times (AOR 7.6, 95\% $\mathrm{Cl} 2.9-16.9$ ) more likely to develop HBV infection than compared to pregnant women with no history of blood transfusion. This is similar to previous studies done elsewhere [17, 18, 34]. However, inconsistent with other studies [40-42]. In fact, in Ethiopia, blood and blood products have been screened for HBV, HCV, HIV, syphilis, and malaria since 2001 [6]. However, in our country, screening for HBV from blood and blood products using ELISA may not detect the virus in the window period and occult hepatitis, which needs molecular techniques for accurate detection of the virus. Evidence showed that a study done in Taiwan, among 10,727 seronegative blood donations, 12 HBV DNA was detected [47]. Therefore, it is advisable to evaluate HBsAg ELISA against molecular techniques.

Participants with a history of tattooing on their body parts (AOR 2, 95\% Cl:1.1-3.7) had more chance of being infected with HBV than pregnant women who did not have tattooing on their body parts. This is in line with studies done in Addis Ababa and Arba Minch, Ethiopia [4, 24]. However, this is contrary to other studies $[39,40]$. The observed differences might be due to variations in sample size of study participants, safety precaution, and culture.

Moreover, study participants with a family history of HBV infection (AOR 3.5,95\% Cl:1.7-3.7) had more likely to be infected with HBV than compared to their counterparts. This is similar to the study done in Tigray, Ethiopia [43]. In contrast, this is inconsistent with other studies [24, 40]. The variations might be due to differences, sample size, and awareness of study participants regarding transmission methods. In Ethiopia, there is a belief that hepatitis disease is not transmitted from person to person; rather, it is Bat's disease or Yewef Beshita in Amharic language [6].

In relation to HIV, pregnant women who had HIV in their blood two times (AOR 2.5, 95\% Cl,1-5.9) more likely develop HBV as compared to HIV-negative pregnant women. HIV is significantly associated with HBV infection. This finding is similar to studies done in Ethiopia and other African countries $[4,18,36]$. This is explained by HBV and HIV shared routes of transmission. HIV and HBV not only share routes of transmission but also, they have reverse transcriptase in a common, target for reverse transcriptase 
inhibitors. Viral hepatitis is a growing cause of mortality among people living with HIV. In sub-Saharan Africa (SSA), an estimated $10 \%$ of HIV-infected individuals are co-infected with HBV [48]. The co-infection rate of HBV and HIV in Ethiopia is a common phenomenon, which leads to increased morbidity and mortality than mono infection of both viruses. HIV negatively impacts the HBV life cycle by increasing persistent HBV infection, having a higher HBV viral load, lower rates of HBeAg loss, increased cirrhosis ,and increased risk of hepatocellular carcinoma [49]. Moreover, HIV-HBV co-infected pregnant women are twice as likely to test positive for HBeAg, three times more likely to have detectable HBV DNA, and have higher HBV DNA serum concentrations as compared to those who are HBV mono-infected, thereby greatly increasing the risk of MTCT [50].

Moreover, in Ethiopia, a systematic review and meta-analysis revealed that the HIV prevalence among pregnant women was $5.7 \%$. This review also reported that HIV in the Amhara region, among pregnant women, was $9.5 \%$ [19]. Despite the recommendation of many international and national HIV guidelines to test HBV among HIV-positive pregnant women before ART initiation, screening uptake is generally poor in Ethiopia. Therefore, screening for HBV among HIV-positive pregnant women is very essential for the mother and the child for prevention of vertical transmission.

Interestingly, pregnant women who had shared their tooth brushes almost 4.5 times (AOR $4.5,95 \% \mathrm{Cl}$ 1.1-18) more likely at risk of getting HBV infection compared to their counterparts. This might be due to during tooth brushing there may be gum bleeding and may transmit HBV from an infected person to a susceptible person. HBV is highly contagious and a hundred times more infectious than HIV and waits more time outside the blood than HIV. It is a tricky enveloped virus transmitted even on surfaces and acts as a non-enveloped virus during transmission [6].

In this study, only $20(1.8 \%)$ pregnant women were vaccinated for HBV prevention. This figure is less than the vaccination status of pregnant women in Gambia 41.3\% [35]. This is due to HBV vaccination in Ethiopia is started lately in 2007 [51]. This is an indication that more efforts were required to vaccinate adults born before 2007 in Ethiopia. Since 1991, the WHO recommended universal HBV vaccination of children and high-risk groups to reduce new infections and prevent progression to cirrhosis and hepatocellular carcinoma [52]. Universal vaccination is exemplary in Taiwan, together with catch-up vaccination and maternal screening, which decreases the prevalence of HBsAg from $9.8 \%$ in 1984 to $0.3 \%$ in 2009 in children younger than 15 years [53]. Likewise, in 2009, the WHO recommended a birth dose vaccine for infants within $24 \mathrm{~h}$ of birth [10]. However, studies have shown that birth dose vaccination may not prevent those infants born from HBeAg-positive pregnant women and have a high viral load of HBV DNA $[8,27]$. Combined treatment with HBV immunoglobulin and birth dose vaccine highly recommended and prevents $85-95 \%$ vertical transmission [52]. However, hepatitis B hyperimmune globulin is expensive and not readily available at most health institutions in Ethiopia. The authors recommended that giving birth dose vaccines within $24 \mathrm{~h}$ of the birth of infants is essential to prevent MTCT and integrate into HIV PMTCT in Ethiopia. Yet it is not a routine practice of provision of the birth dose vaccines in Ethiopian health institutions. 
Therefore, the findings of this study will provide insights for policy makers to implement routine practice of screening of HBV and HCV in pregnant women and immunization of infants for HBV and integration into PMTCT of HIV. However, this study has some limitations. The molecular DNA test is better for diagnosing occult hepatitis has not done in this study, which may underestimate the prevalence of HBV among pregnant women.

\section{Conclusion And Recommendations}

$\mathrm{HBV}$ and $\mathrm{HCV}$ infections are intermediate among pregnant women in the Amhara region. This finding suggests that $4.6 \%$ and 1.6 of infants born to HBV and HCV-infected pregnant women are more likely at risk of contracting infection vertically from their mothers in the Amhara region. We advocate that the integration of HBV and HCV-infected pregnant women into PMTCT is important in Ethiopia. Factors such as being HIV-positive, history of multiple sexual partners, blood transfusion, tattooing, family history of hepatitis, and sharing of tooth brushes were significant predictors of HBV infection. Therefore, providing health education on HBV and HCV transmission, risk behaviors, vaccination, screening of all pregnant women, and provision of a birth dose vaccine for newly born infants within 24 hours is recommended to prevent MTCT. Moreover, further longitudinal MTCT and molecular studies will be recommended on HBV and HCV in Ethiopia.

\section{Declarations}

\section{Acknowledgement}

We are very grateful for the University of Gondar for funding this research. We also acknowledge data collectors for their great support. Finally, we would like to extend our gratitude to the study participants.

\section{Funding}

University of Gondar funding this study.

\section{Availability of data and materials}

Data are available upon reasonable request from the corresponding author.

\section{Authors' contribution}

MD, conceptions of research proposal, data collection, laboratory work, conducted data analysis and interpreted the results and drafted the manuscript. MT, FM and MA were assisted in interpreting the results, and reviewing the initial and final drafts of the manuscript. YM, SE, MG GY, and LA were involved in data collection, data analysis, reviewing the initial and final drafts of manuscripts. All authors have read and approved the final manuscript. 


\section{Competing interest}

We declare that we have no competing interests.

\section{Consent for publication}

Not applicable.

\section{Ethics approval and consent to participate}

Ethical approval for the study was obtained from the Institutional Review Board (IRB) of the University of Gondar. Written informed consent was obtained from each pregnant woman before enrolling in this study. Study participants anonymity was maintained throughout the study. Study participants were identified only by their code numbers. Confidentiality of information was maintained by locking the information using a computer password. Those patients positive for HBsAg and anti-HCV antibody were referred for better management

\section{Competing interest}

We declare that we have no competing interests.

\section{References}

1. WHO: Combating hepatitis B and C to reach elimination by 2030. Advocacy Brief 2016.

2. Wendy Spearman MA, Reidwaan Ally, Betty Apica, Lina Cunha, Dusheiko G: Hepatitis B in subSaharan Africa: strategies to achieve the 2030 elimination targets. The lancet 2017; 2(12):900-909.

3. Mohd Hanafiah K, Groeger J, Flaxman AD, Wiersma ST: Global Epidemiology of Hepatitis C Virus Infection: New estimates of age-specific antibody to HCV seroprevalence. . Hepatology 2013; 57(4).

4. Desalegn Z, Wassie L, Bedimo H, Mihret A, Yehenew A: Hepatitis B and human immunodeficiency virus co-infection among pregnant women in resource-limited high endemic setting, Addis Ababa, Ethiopia: implications for prevention and control measures . Eur J Med Res 2016; 21(16).

5. Lam N, Gotsch PB, Langan RC, : Caring for pregnant women and newborns with hepatitis B or C. Am Fam Phys 2010; 82(10):1225-1229.

6. Shiferaw F, Letebo M, Bane A: Chronic viral hepatitis: policy, regulation, and strategies for its control and elimination in Ethiopia. BMC Public Health 2016, 16:769.

7. Custer B, Sullivan SD, Hazlet TK, lloeje U, Veenstra DL, Kowdley KV: Global epidemiology of hepatitis B virus. Journal of clinical gastroenterology 2004; 38(10):S158-S168.

8. Kean E, Funk Al, Shimakawa Y: Systematic review with meta-analysis : the risk of mother to child transmission of HBV infection in Sub-Sahran Africa.A2016;44:1005-1017. Aliment Pharmacol Ther 2016;44:1005-1017. 
9. Breakwell L, Tevi-Benissan C, Childs L, Mihigo R, Tohme R: The status of hepatitis B control in the African region. . The Pan African Medical Journal 2017, 27(3).

10. WHO.: Global hepatitis report, 2017. Geneva: World Health Organization, April, 2017. www.who.int/hepatitis/publications/globalhepatitis accessed september 20, 2019. 2017.

11. Kanninen TT, Dieterich D, Asciutti S HCV vertical transmission in pregnancy: new horizons in the era of DAAs. Hepatology 2015; 62:1656-1658.

12. Organization. WH: Hepatitis C factsheet no 164. Geneva: World Health Organization. 2017.

13. Fauteux-Daniel S, Larouche A, Calderon V, Boulais J, Béland C, Ransy DG, Boucher M, Lamarre V, Lapointe N, Boucoiran I et al. Vertical transmission of hepatitis C virus: variable transmission bottleneck and evidence of midgestation in utero infection. $J$ Viro/ 2017, 91.

14. Sookoian S. Liver disease during pregnancy: acute viral hepatitis. Ann Hepatol 2006, 5(3):231-236.

15. Regea Dabsu, Eyasu Ejeta: Seroepidemiology of Hepatitis B and C Virus Infections among pregnant women attending antenatal clinic in selected Health Facilities in east Wollega Zone, west Oromia, Ethiopia. Hindawi BioMed Research International 2018.

16. Semaw A, Awet H, Yohannes M: Sero-prevalence of hepatitis B surface antigen and associated factors among pregnant mothers attending antenatal care service, Mekelle, Ethiopia: evidence from institutional based quantitative cross-sectional study. World Academy of Science, Engineering and Technology: Medical and Health Sciences 2015;2(9).

17. Molla S, Munshea A, Nibret E: Seroprevalence of hepatitis B surface antigen and anti HCV antibody and its associated risk factors among pregnant women attending maternity ward of Felege Hiwot Referral Hospital, northwest Ethiopia: a cross-sectional study. virology journal 2015; 12(204):1-9.

18. Mekonnen R, Admasu D, Belete M Sero-Prevalence of Hepatitis B Virus and associated factors among pregnant mothers attending antenatal care in Public Health Facilities, Dire Dawa. J Med Microb Diagn 2018; 7(281).

19. Geremew D , Tajebe F, Ambachew S, Endalamaw A, Eshetie S: Seroprevalence of HIV among pregnant women in Ethiopia: a systematic review and meta-analysis. BMC Res Notes 2018; 11(908).

20. CDC. Recommendations for identification and public health management of persons with chronic hepatitis B virus infection.MMWR 2008; 57(8):56-63.

21. (NICE) NIfHaCE: Ante-natal care. Routine care for healthy pregnant women. National Collaborating Center for Women's and Children's Health 2008; 62.

22. Wang AL, Qiao YP, Wang LH, Fang LW, Wang F, Jin X: Integrated prevention of mother-to-child transmission for human immunodeficiency virus, syphilis and hepatitis B virus in China. Bull World Health Organ 2015;93:52-56.

23. Schweitzer A, Horn J, Mikolajczyk RT, Krause G, JJ. O: Estimations of worldwide prevalence of chronic hepatitis B virus infection: a systematic review of data published between 1965 and 2013. Lancet 2015; 386 (10003):1546-1555. 
24. Yohanes T, Zerdo Z, Chufamo N: Seroprevalence and Predictors of Hepatitis B Virus Infection among Pregnant Women Attending Routine Antenatal Care in Arba Minch Hospital, South Ethiopia. Hepatitis Research and Treatment 2016.

25. Seid M, Gelaw B, Assefa A: Sero-prevalence of HBV and HCV infections among pregnant women attending antenatal care clinic at Dessie referral hospital.Ethiopia Adv Life Sci Health 2014; 1(2):109120.

26. Kishk R, Mandour M, Elprince M, Salem A, Nemr N, Eida M, Ragheb M: Pattern and interpretation of hepatitis B virus markers among pregnant women in North East Egypt. Braz J Microbio/ 2019.

27. Chotun N, Preiser W, van Rensburg CJ, Fernandez P, Theron GB, Glebe D: Point-of-care screening for hepatitis B virus infection in pregnant women at an antenatal clinic: A South African experience. Plose One 2017; 12(7).

28. Sheng QJ, Wang SJ, Wu YY, Dou XG, Ding YH: Hepatitis B virus serosurvey and awareness of motherto-child transmission among pregnant women in Shenyang, China. An observational study. Medicine 2018; 97(22):1-5.

29. Dabsu R, Ejeta E: Seroepidemiology of Hepatitis B and C Virus Infections among Pregnant Women Attending Antenatal Clinic in Selected Health Facilities in East Wollega Zone, West Oromia, Ethiopia. . Hindawi BioMed Research International 2018; 2018.

30. Chernet A, Yesuf A, Alagaw A: Seroprevalence of Hepatitis B surface antigen and factors associated among pregnant women in Dawuro zone, SNNR, Southwest Ethiopia,Across sectional study. BMC research notes 2017; 10(418).

31. Tegegne D, Desta K, Tegbaru B, Tilahun T: Seroprevalence and transmission of hepatitis B virus among delivering women and their new born in selected health facilities, Addis Ababa, Ethiopia: a cross sectional study. BMC Res Notes 2014; 7(239).

32. Fessehaye N, Berhane A, Ahmed H, Mohamed S, Tecle F, Gikunju J, E. O: Prevalence of Hepatitis B Virus Infection and Associated Seromarkers among Pregnant Women in Eritrea. . J Hum Virol Retrovirol 2018; 6(1).

33. Lobstein S, Faber R, Tillmann HL: Prevalence of hepatitis B among pregnant women and its impact on pregnancy and newborn complications at a tertiary hospital in the eastern part of Germany. Digestion 2011; 83:76-82.

34. Cetin S, Cetin M, Turhan E, Dolapcioglu K Seroprevalence of hepatitis B surface antigen and associated risk factors among pregnant women. J infect Dev Ctries 2018; 12(10):904-909.

35. Bittaye M, Idoko P, Ekele BA, Amenyi Obed S, Nyan O: Hepatitis B virus sero-prevalence amongst pregnant women in the Gambia. BMC Infectious Diseases 2019; 19(259).

36. Manyahi J, Msigwa Y, Mhimbira F, Majigo M: High sero-prevalence of hepatitis B virus and human immunodeficiency virus infections among pregnant women attending antenatal clinic at Temeke municipal health facilities, Dar es Salaam,Tanzania: a cross sectional study BMC Pregnancy and Childbirth 2017, 17(109). 
37. Frempong MT, Ntiamoah P, AnnaniAkollor ME, Owiredu WKBA, Addai-Mensah O, Owiredu E-W: Hepatitis B and C infections in HIV-1 and non-HIV infected pregnant women in the Brong-Ahafo Region, Ghana. PLoS ONE 2019; 14(7).

38. Eyong EM , Yankam BM, Seraphine E, Ngwa CH, Nkfusai NC, Anye CS, Nfor GK, SM NC: The prevalence of HBsAg, knowledge and practice of hepatitis B prevention among pregnant women in the Limbe and Muyuka Health Districts of the South West region of Cameroon: a three-year retrospective study. Pan African Medical Journal 2019; 32(122).

39. Metaferia Y, Dessie W, Ali I, Amsalu A: Sero-prevalence and associated risk factors of Hepatitis B virus among pregnant women in Southern Ethiopia," A Hospital based cross-sectional study. Epidemiology and health 2016; 38(27):1-7.

40. Amsalu A, Ferede F, Eshetie S, Tadewos A, Assegu D: Prevalence, infectivity, and associated risk factors of hepatitis B virus among pregnant women in Yirgalem Hospital, Ethiopia: implication of screening to control mother-to-child transmission Hindawi Journal of Pregnancy 2018;10:1-81.

41. Tunje A, Andargie M, Hiko M, Fikru C, Kejela G: Sero-prevalence of hepatitis B virus and associated factors among pregnant women in Gambella hospital, South Western Ethiopia: facility based crosssectional study. BMC Infectious Diseases 2019; 19(602).

42. Umare A, Seyoum B , Gobena T, Haile Mariyam T: Hepatitis B Virus Infections and Associated Factors among Pregnant Women Attending Antenatal Care Clinic at Deder Hospital, Eastern Ethiopia. PLOS ONE 2016; 11(11).

43. Mezgebo TA, Niguse S, Gebrekidan Kahsay A, Hailekiros H, Berhe N, Asmelash Dejene T: Hepatitis B virus infection and associated risk factors among pregnant women attending antenatal care in health facilities of Tigray, Northern Ethiopia. J Med Virol 2018; 90:503-509.

44. Bafa TB, DA E: Seroepidemiological patterns and predictors of hepatitis B, C and HIV viruses among pregnant women attending antenatal care clinic of Atat Hospital, Southern Ethiopia. SAGE Open Medicine 2020;8:1-9.

45. Chibwe E, Silago V, Kajoro E, Juma M, Mkumbo E, Minja CA, Mujuni F, Stephen E, Mshana SE , MM M: Antihepatitis B Surface Antigen and Hepatitis C Antibodies among Pregnant Women in an Urban Area of Mwanza City, Tanzania. Hindawi Journal of Pregnancy 2019;2019.

46. Khamis H H, Farghaly AG, Shatat H Z., EM. E-G: Prevalence of hepatitis $\mathrm{C}$ virus infection among pregnant women in a rural district in Egypt. Tropical Doctor 2016; 46(1):21-27.

47. Li L, Chen PJ, Chen MH, Chak KF, Lin KS, Tsai SJ: A pilot study for screening blood donors in Taiwan by nucleic acid amplification technology: detecting occult hepatitis $B$ virus infections and closing the serologic window period for hepatitis $C$ virus. Transfusion 2008;48(6):1198-1206.

48. Stabinski L, O'Connor S, Barnhart M, Kahn RJ, Hamm TE: Prevalence of HIV and hepatitis B virus coinfection in sub-Saharan Africa and the potential impact and program feasibility of hepatitis $B$ surface antigen screening in resource-limited settings. J Acquir Immune Defic Syndr 2015; 68(3).

49. CL T: Hepatitis B and human immunodeficiency virus coinfection. Hepatology 2009; 49(5). 
50. Kourtis AP, Bulterys M, Hu DJ, Jamieson DJ: HIV-HBV co-infection-a global challenge. N Engl J Med 2012;366:1749-1752.

51. Federal, Democratic, of R, Ethiopia.: National expanded programme on immunization comprehensive multi-year plan 2011-2015. Addis Ababa: Fedral Ministry of Health. 2010.

52. Cassidy A, Mossman S, Olivieri A, De Ridder M, Leroux-Roels G: Hepatitis b vaccine effectiveness in the face of global hbv genotype diversity. Expert review of vaccine 2011; 10(12):1709-1715.

53. Chan CY, Lo KJ, Lee SD: Legend of hepatitis B vaccination: The Taiwan experience literature review. Journal of gasteroenterology and Hepatology 2004;19(2):121-126.

\section{Tables}

Table1. Sociodemographic characteristics of pregnant women attending in the Amhara region referral hospitals from May1,2018 to September 30,2019 . 


\begin{tabular}{|c|c|c|}
\hline Characteristics & Category & Number (\%) \\
\hline \multirow[t]{2}{*}{ Age in year } & $17-25$ & $464(39.6)$ \\
\hline & $26-45$ & $657(60.4)$ \\
\hline \multirow[t]{4}{*}{ Marital status } & Single & $17(1.5)$ \\
\hline & Married & 1094(97.6) \\
\hline & Windowed & $1(0.1)$ \\
\hline & Divorced & $9(0.8)$ \\
\hline \multirow[t]{2}{*}{ Residence } & Urban & 895(79.8) \\
\hline & Rural & $226(20.2)$ \\
\hline \multirow[t]{4}{*}{ Religion } & Orthodox & $1064(94.9)$ \\
\hline & Muslim & $49(4.4)$ \\
\hline & Protestant & $7(0.6)$ \\
\hline & Catholic & $1(0.1)$ \\
\hline \multirow[t]{3}{*}{ Income } & $<1000$ & $159(14.2)$ \\
\hline & $1000-4000$ & $799(71.3)$ \\
\hline & $>4000$ & $163(14.5)$ \\
\hline \multirow[t]{5}{*}{ Educational status } & No education & $254(22.7)$ \\
\hline & Read and write & $61(54)$ \\
\hline & Primary & $173(15.4)$ \\
\hline & High school & $302(26.9)$ \\
\hline & College\& above & $331(29.5)$ \\
\hline \multirow[t]{5}{*}{ Occupation } & Housewife & $732(65.3)$ \\
\hline & Employed & 191(17) \\
\hline & Daily laborers & $92(8.2)$ \\
\hline & Student & $33(2.9)$ \\
\hline & Others & $73(6.5)$ \\
\hline \multirow[t]{2}{*}{ Gravida } & Primigravida & 409 (36.5) \\
\hline & multigravida & $712(63.5)$ \\
\hline \multirow[t]{2}{*}{ Parity } & Nullipara & $545(48.6)$ \\
\hline & Multipara & $576(51.4)$ \\
\hline \multirow[t]{2}{*}{ Vaccination history } & Yes & $20(1.8)$ \\
\hline & No & $1101(98.2)$ \\
\hline \multirow[t]{3}{*}{ Study site } & UOGCSH & $593(52.9)$ \\
\hline & FHCSH & $447(39.9)$ \\
\hline & $\mathrm{DMH}$ & $81(7.2)$ \\
\hline
\end{tabular}

Table 2. Bivariate analysis of sociodemographic characteristics in relation with HBV infection among pregnant women in the Amhara region hospitals from May1,2018 to September 30,2019. 


\begin{tabular}{|c|c|c|c|c|c|}
\hline \multirow[t]{2}{*}{ Characteristics } & \multirow[t]{2}{*}{ Category } & \multirow[t]{2}{*}{ Number (\%) } & \multicolumn{2}{|c|}{ HBV status } & \multirow[t]{2}{*}{ Crude odds ratio $(\mathrm{COR})(95 \% \mathrm{CI})$} \\
\hline & & & Pos & Neg & \\
\hline \multirow[t]{2}{*}{ Religion } & Orthodox & $987(95.0)$ & $44(4.5)$ & $943(95.5)$ & 1 \\
\hline & Others & $52(5)$ & $4(7.7)$ & 48(92.3) & 1.98(.67-5.8) \\
\hline \multirow[t]{2}{*}{ Residence } & Urban & 895(79.8) & $38(4.2)$ & $857(95.8)$ & 1 \\
\hline & Rural & $226(20.2)$ & $14(6.2)$ & 212(93.8 & $1.5(.79-2.8)$ \\
\hline \multirow[t]{2}{*}{ Marital status } & Married & 1017(97.8) & $43(4.2)$ & 974(95.8) & 1 \\
\hline & Unmarried & $23(2.2)$ & $5(21.7)$ & 18(78.3) & $3.9(1.5-9.6)^{*}$ \\
\hline \multirow[t]{2}{*}{ Age } & $17-25$ & $464(39.6)$ & $30(6.5)$ & $434(93.5)$ & $2(1.1-3.5)$ \\
\hline & $26-45$ & $657(60.4)$. & $22(3.3)$ & 635(96.7) & 1 \\
\hline \multirow[t]{3}{*}{ Income } & $<1000$ & $159(14.2)$ & $15(9.4)$ & $144(90.6)$ & $.37(0.2-0.7 .0)$ \\
\hline & $1000-4000$ & $799(71.3)$ & $30(3.8)$ & $769(96.2)$ & 1 \\
\hline & $>4000$ & 163(14.5) & $7(4.3)$ & 156(95.7) & \\
\hline \multirow[t]{3}{*}{ Education } & No education & $254(22.7)$ & $14(5.5)$ & $240(94.5)$ & $1.77(.68-4.5)$ \\
\hline & Primary + RW & $234(20.9)$ & $11(4.7)$ & 223(95.3) & $1.64(.58-4.6)$ \\
\hline & High school \& above & $633(56.5 .4)$ & $27(4.3)$ & 606(95.7) & $1.07(.39-2.9)$ \\
\hline \multirow[t]{3}{*}{ Occupation } & Housewife & $522(62.4)$ & $23(4.4)$ & 499(95.8) & $1.49(.51-4.4)$ \\
\hline & Employed & $140(16.8)$ & $5(3.6)$ & 135(96.4) & 1 \\
\hline & Others & $174(20.8)$ & $9(5.2)$ & $165(94.8)$ & $1.9(.56-6.15)$ \\
\hline \multirow[t]{2}{*}{ Gravida } & Primigravida & $409(36.5)$ & $24(5.9)$ & $385(94.1)$ & $1.2(.62-2.4)$ \\
\hline & multigravida & $712(63.5)$ & $28(3.9)$ & $684(961)$ & 1 \\
\hline \multirow[t]{2}{*}{ Parity } & Nullipara & $545(48.6)$ & $33(6.1)$ & $512(93.9)$ & $1.85(.92-3.7)$ \\
\hline & Multipara & $576(51.4)$ & $19(3.5)$ & $557(96.7)$ & 1 \\
\hline
\end{tabular}

Others- muslim, protestant and catholic, RW=Write and Read $\quad * *=\mathrm{P}<0.001, *=\mathrm{P}<0.5$

Table 3. Bivariate and multivariate analysis of factors associated with HBV infection among pregnant women in the Amhara region hospitals from May1,2018 to September 30,2019. 


\begin{tabular}{|c|c|c|c|c|c|c|}
\hline \multirow[t]{2}{*}{ Variable } & \multirow[t]{2}{*}{ Category } & \multirow[t]{2}{*}{ Number } & \multicolumn{2}{|c|}{ HBV status } & \multirow[t]{2}{*}{ COR } & \multirow[t]{2}{*}{ Adjusted Odds ratio AOR $(95 \% \mathrm{CI})$} \\
\hline & & & Pos & Neg & & \\
\hline \multirow[t]{2}{*}{ Age } & $17-25$ & $464(39.6)$ & $30(6.5)$ & $434(93.5)$ & $2(1.1-3.5)$ & $2.5(1.3-4.5)^{*}$ \\
\hline & $26-45$ & $657(60.4)$ & $22(3.3)$ & 635(96.7) & 1 & \\
\hline \multirow[t]{2}{*}{ Marital status } & Married & 1017(97.8) & $43(4.2)$ & 974(95.8) & 1 & \\
\hline & Unmarried & $23(2.2)$ & $5(21.7)$ & 18(78.3) & $4.5(1.9-10.6)$ & \\
\hline \multirow[t]{2}{*}{ Tattoo } & Yes & $351(31.3)$ & $23(6.6)$ & $328(93.4)$ & $1.8(1.0-3.1)^{*}$ & $2(1-3.8)^{*}$ \\
\hline & No & $770(68.7)$ & $29(3.8)$ & $741(96.2)$ & 1 & \\
\hline \multirow[t]{2}{*}{ Dental extraction } & Yes & 156(13.9) & $6(3.8)$ & $150(96.2)$ & $1.3(.53-3)$ & \\
\hline & No & $965(86.1)$ & $46(4.8)$ & $919(95.2)$ & 1 & \\
\hline \multirow[t]{2}{*}{ Blood transfusion } & Yes & $34(3)$ & $7(20.6)$ & $27(79.4)$ & $6(2.5-15)^{* * *}$ & $7.6(2.9-16.9)^{* *}$ \\
\hline & No & 1087(97) & $45(4.1)$ & 1042(95.9.) & 1 & \\
\hline \multirow[t]{2}{*}{ Surgery } & Yes & $78(8.3)$ & $3(3.8)$ & $75(96.2)$ & $.8(.24-2.7)$ & \\
\hline & No & 1043(91.7) & $49(4.7)$ & 994(95.3) & 1 & \\
\hline \multirow[t]{2}{*}{ Sexual trans. Dis. } & Yes & 138(12.3) & $9(6.5)$ & 129(93.5) & $.65(.31-1.3)$ & \\
\hline & No & 983(87.7) & $43(4.4)$ & $940(95.6)$ & 1 & \\
\hline \multirow[t]{2}{*}{ HIV } & Yes & 113(10.1) & $10(8.8)$ & 103(91.2) & $2.2(1.09-4.6)$ & $2.5(1-5.9)^{*}$ \\
\hline & No & 1008(89.9) & $42(4.2)$ & 966(95.8) & 1 & \\
\hline \multirow[t]{2}{*}{ Abortion } & Yes & 203(16) & $9(4.4)$ & 194(95.6) & $1.1(0.5-2.2)$ & \\
\hline & No & $918(81.9)$ & $43(4.7)$ & 875(95.3) & 1 & \\
\hline \multirow[t]{2}{*}{ Unprotected sex } & Yes & $84(7.5)$ & $6(7.1)$ & 78(92.9) & $1.6(.68-4.0)$ & \\
\hline & No & $1037(92.5)$ & $46(4.4)$ & $991(95.6)$ & 1 & \\
\hline \multirow[t]{2}{*}{ Multiple sexual partner } & Yes & $61(5.4)$ & $7(11.5)$ & $54(88.5 \%)$ & $3.9(1.8-8.4)$ & $3.2(1.3-7.6)$ \\
\hline & No & $1060(94.6)$ & $45(4.2)$ & 1015(95.8) & 1 & 1 \\
\hline \multirow[t]{2}{*}{ Ear pricing } & Yes & $248(22.1)$ & 18(7.3) & $230(92.7)$ & $1.9(1-3.5)^{*}$ & \\
\hline & No & $873(77.9)$ & $34(3.9)$ & 839(96.1) & 1 & \\
\hline \multirow[t]{2}{*}{ Nose piercing } & Yes & $50(4.5 \%)$ & $6(12 \%)$ & $44(88 \%)$ & $3(1.2-7.5) *$ & 0.145 \\
\hline & No & 1071(95.5) & $46(4.3 \%)$ & 1025(95.7\%) & 1 & \\
\hline \multirow[t]{2}{*}{ Diabetes } & Yes & $25(2.2)$ & $3(12)$ & $22(88)$ & $2.9(.84-10$ & $2.8(0.7-11)$ \\
\hline & No & 1096(98.2) & $49(4.5)$ & 1047(95.5) & 1 & \\
\hline \multirow[t]{2}{*}{ Hospitalization . } & Yes & 144(12.8) & $6(4.2)$ & 138(95.8) & $0.88(.36-2)$ & \\
\hline & No & $977(87.2)$ & $46(4.7)$ & $931(95.3)$ & 1 & \\
\hline \multirow[t]{2}{*}{ Family history of HBV } & Yes & $99(8.8)$ & $11(11.1)$ & $88(88.9)$ & $3(1.5-6)$ & $3.5(1.7-7.6)^{* *}$ \\
\hline & No & $981(91.2)$ & $41(4)$ & 981(96) & 1 & \\
\hline \multirow[t]{3}{*}{ Sharing tooth brush } & Yes & 18(1.6) & $3(16.7)$ & 15(83.3) & $4.3(1.2-15)$ & \\
\hline & & & & & & $4.5(1.1-18)^{*}$ \\
\hline & No & 1103(98.4) & $49(4.4)$ & 1054(95.6) & 1 & \\
\hline \multirow[t]{2}{*}{ Sharing sharp material } & Yes & $62(4.5)$ & $3(4.8)$ & $59(95.2)$ & $1.0(.28-4.3)$ & \\
\hline & No & $1059(94.5)$ & $49(4.6)$ & $1010(95.4)$ & 1 & \\
\hline
\end{tabular}

